\title{
Effects of Malaria in Pregnancy (MiP) on Pregnancy Development and its Outcome: a Critical Review
}

\author{
Joshua Djabanor ${ }^{1}$, Elvis Quansah ${ }^{1}$, Du-Bois Asante ${ }^{1,2^{*}}$ \\ ${ }^{1}$ Department of Biomedical Sciences, School of Allied and Health Sciences, College of Health and Allied Sciences, University of Cape Coast-Ghana. \\ ${ }^{2}$ Department of Forensic Sciences, School of Biological Sciences, College of Agriculture and Natural Sciences, University of Cape Coast- Ghana.
}

\section{ARTICLE INFO}

Article history:

Received on: 29/05/2016

Accepted on: 28/07/2016

Available online: 20/03/2017

Key words:

Malaria, Pregnancy, Placental malaria, VAR2CSA, Placental pathology.

\begin{abstract}
Malaria is the most important tropical parasitic infection in humans all over the world, and very common in developing countries especially in the tropical zones. The protozoan parasites Plasmodium falciparum, $P$. vivax, $P$. malariae and $P$. ovaleare transmitted through the bite of sporozoite-infected female Anopheles mosquitoes to cause malaria in humans. Malaria in pregnancy (MiP) is a clinical situation in which a pregnant woman is infected with Plasmodium parasite resulting in malaria. MiP is detrimental to both the pregnant woman and her fetus, and it remains as one of the major causes of infant mortality in malaria endemic regions especially in Sub-Saharan Africa. It causes several histopathological changes within the placenta and umbilical cord which manifest in several clinical symptoms. It is one of the key contributors to preterm delivery, low birth weight, intrauterine growth retardation (IUGR), miscarriage, intrauterine death, poor neurodevelopment and immunosuppression in infants. Most distinct systemic proinflammatory responses in pregnancy are characteristics of severe malaria, and excessive activation of the immune system is central to the pathophysiology of placental malaria. There is extensive research on VAR2CSA and its contribution to placental sequestration. Currently, VAR2CSA protein is being made into pregnancy malaria specific vaccines for non-immune mothers to reduce placental malaria infection. This review summarizes the evidences, currently known clinically significant manifestations and the ultimate effect of MiP on pregnancy development.
\end{abstract}

\section{INTRODUCTION}

Prevalence of Malaria started reducing gradually since the last one and half decades though still pervasive all around the globe. It intimidates the lives of about $40 \%$ of the world's population worldwide [1, 2], the majority of whom are young children (under 5 years of age) and pregnant women [2]. World Malaria Report (WMR) from the World Health Organization shows a decline in malaria cases by $25 \%$ globally and $33 \%$ in Africa from 2000 to 2015 under the context of the Millennium Development Goal (MDG) project. It was estimated that about $85 \%$ of malaria cases in the world occur in Sub-Saharan Africa in 2015 [3]. According to WMR 2015, there were about 214 million malaria cases globally in 2015, and 438000 malaria deaths, representing a decrease in malaria incidence and deaths of $37 \%$ and $60 \%$ since 2000 , respectively. Malaria is a protozoan disease transmitted by female Anopheles mosquitoes usually Anopheles

* Corresponding Author

Email: duasante@ucc.edu.gh gambiae and A. funestus in Africa [4]. It is caused by four main plasmodial parasites namely Plasmodium falciparum, $P$. vivax, $P$. malariae, and $P$. ovale transmitted through the bite of a sporozoite infected female Anopheles mosquito [1]. Other Plasmodium species also cause malaria in mammals other than humans. These include $P$. knowlesi which cause malaria in monkeys and $P$. berghe $i$ which is associated with rodents [5].

Among the four species, infection with $P$. falciparum is the most deadly and common in Africa [6] which differs from other human malarial parasites. This is because infected red blood cells (IRBC) do not remain in circulation for the entire life cycle of the erythrocytic phase [7]. However, after 24-36 hours, when young parasites mature from the merozoite to the trophozoite stage, IRBC adhere to endothelial cells in the microcirculation of various organs [7, 8, 9]. This process is known as sequestration, and is believed to occur in order to avoid splenic removal of IRBC [7, 10, 11]. Sequestration causes microcirculatory obstruction, impaired tissue perfusion, inflammatory cells activation, and also contributes to the most severe manifestations of malaria infection caused by $P$. falciparum $[12,13]$. 
Malaria in pregnancy is a clinical condition in which pregnant women are infected with malaria parasites [14]. This remains a major public health challenge in tropic zones especially in Sub-Saharan Africa [14-16]. A study conducted in Lagos of Nigeria showed the prevalence of $52 \%$ among pregnant women attending to antenatal care (ANC) [17]. In a similar study in Enugu State of Nigeria, about $99 \%$ of pregnant women who visited hospitals with signs and symptoms of malaria had at least some level of parasitaemia [18]. Report from a comparative study in Sub-Saharan Africa showed that about $20 \%$ of pregnant women attending to the ANC are positive for malaria parasites while about $72 \%$ of pregnant women had malaria at least once during their gestation period [19]. President Malaria Initiative (PMI) - Ghana, reported that about $20 \%$ outpatients are pregnant women. It continued that averagely $68.8 \%$ of pregnant women suffered malaria episode at least once during their gestation period in 2014 [20]. In areas of low transmission of the parasite with low acquired immunity, pregnant women are highly susceptible to episodes of severe malaria which may result is several obstetric challenges such as still birth and spontaneous abortion [3, 13]. In areas of high transmission where acquired immunity is high, pregnant women are susceptible to asymptomatic infections which may result in maternal anemia and placental pathologies, each of which has a specific health consequence $[3,12,21]$. The pathological changes due to malaria have a deleterious impact on physiological processes of pregnancy and more fatal in clinically non-immune primigravid mothers [9-14]. These changes are taught to be linked to maternal immunosuppression during pregnancy to accommodate the semi-allogenic fetus $[10,22]$. Malaria in pregnancy is significantly associated with higher infant mortality and morbidity [20], including cerebral malaria [23], maternal anemia, intrauterine growth retardation [24], premature labor [25], stillbirth, Low birth weight (LBW) [26-28] and untimely abortions of developing embryos and fetus [3, 27]. It was reported that about $11 \%$ of neonatal mortality and up to $14 \%$ LBW in malaria endemic regions in Africa are as a result of pregnancy complications due to malaria infection [3].

\section{PATHOPHYSIOLOGY OF MALARIA}

Plasmodium species are intracellular parasites [29] with two phases of life cycle in human host; thus hepatic stage where the sporozoites invade hepatocytes and develop to the merozoites, and the erythrocytic stage where merozoites invade red blood cells (RBC) causing haemolysis to release several trophozoites into circulation [30]. P. falciparum induce a number of significantly fatal pathological conditions in the liver [7], spleen [31], brain resulting in cerebral malaria $(\mathrm{CM})[24,32]$ and placenta, causing placental malaria [33, 34]. Common clinical presentations of infection with all four Plasmodium species are periodic paroxysm, chills, rigor, sweating, body aches, headache, nausea, general body weakness and prostration [30-32, 35] which are similar to fever in other non-malaria infections [31]. Therefore it is almost impossible to differentiate malaria febrile illness from fevers caused by other etiological agents, especially in areas of high malaria endemicity where incidental parasitaemia is common and diagnostic capacity is limited [29]. Studies conducted elsewhere reported that a synchronous malarial infection is as a result of coordinated rupture of IRBCs leading to the prototypical malarial fevers [36]. In severe and chronic states, malaria parasites may migrate into the brain to cause CM [37].

Studies have shown that subendothelial deposition of immune complexes containing $\operatorname{IgG}, \operatorname{IgM}$ and $\mathrm{C} 3$, and to some extent, malaria antigens contribute to quartan malaria nephropathy (QMN) [7]. This finding coincides with observations of pathogenesis of malaria acute renal failure (MARF) which is in turn, a potential cause of edema and pregnancy induced hypertension in four malaria endemic regions studied [38]. Haemolysis as a result of endothelial activation and hemodynamic alteration is a potential cause of acute tubular necrosis and acute interstitial nephritis [37]. Jaundice and liver dysfunction are common in severe malaria caused by P. falciparum in malarious regions [7, 39]. Most of the hepatic pathologies occur during the pre-erythrocytic cycle where the merozoite circumsporozoite protein A (CSP-A) and thrombospondin related adhesive proteins (TRAP) protein bind to the hepatocytes via the heparin sulphate glycosylaminoglycans (HSG) $[32,37]$ and enters the hepatocytes. The sporozoites enter the hepatocyte and form parasitophorous vacuole and surround themselves with a thin layer of merosomes $[32,40]$. The presence of Plasmodium in the hepatocyte results in Kupffer cell hyperplasia and activation, whereas in the erythrocytic cycle, the parasite induces an intravascular haemolysis resulting in jaundice and haemosiderosis [38, 41]. Studies conducted using laboratory mice models, reported histopathological evidence of congestion of hepatic vessels due to portal occlusion, swollen hepatocytes, centrizonal necrosis, steatosis, cholestasis, cytoplasmic vacuole induction and dilatation of hepatic sinuses in Plasmodium infection [41, 42].

Report from several researchers indicates that splenic disturbances occur during acute malarial infection [43, 44]. A patient suffering from pain in the left-upper-quadrant of the abdomen was observed to have been infected with malaria which resulted in splenic rupture and infarction with a gross macroscopic investigation revealing evidence of splenomegaly [43]. Microscopic studies revealed white pulp expansion and a diffused hypercellularity in the splenic red pulp, with intense proliferating plasmablasts in the subcapsular and perivascular compartments in nonimmune malaria patients [45]. Most patients with acute infection especially with $P$. vivax show follicular hyperplasia with active germinal centers and stretching of splenic parenchyma and capsule $[45,46]$. A study conducted elsewhere in P. berghei infected mice reported hyperplasia of the spleen within white and red pulp, and the evidence of haemosiderosis [41].

\section{MALARIA INDUCED ANEMIA (MIA) IN PREGNANCY}

One major raw material for $\mathrm{RBC}$ production in human is iron. During pregnancy, there is a higher demand for $\mathrm{RBC}$ 
production. Iron deficiency is one of the most common causes of malaria induced anaemia in pregnant women [47]. Majority of women start pregnancy with at least a certain level of iron deficiency which is intensified by physiological change of haemodilution that occur in pregnancy, and usually start from the first trimester till birth [48]. It is well established that iron is one of the requirements for growth of malaria parasites in human host $[49,50]$. When a pregnant woman is infected with malaria, the parasites compete with the woman for the already insufficient iron [50]. This sort of interspecific competition between the Plasmodium and the pregnant woman probably results in further reduced plasma iron concentration leading to microcytic anaemia. In the case where iron deficiency is coupled with folic acid and vitamin B12 deficiency, anisocytosis is resulted where RBCs have unequal sizes[49].

Merozoites floating in the blood stream randomly collide and bind with RBCs [51]. The binding of merozoites and RBC occur through interaction between merozoites surface protein 1 (MSP-1) and Band 3 on RBC [8]. The content of micronemes is released into the binding site to stabilize the bond formed between the merozoites and RBC [52]. Apical membrane antigen-1 (AMA1) released by the merozoites help the parasite to re-orient itself for tight junction formation and effective binding [53, 54]. Different species of malaria parasite release different antigen to facilitate binding. For instance, P. falciparum releases Erythrocyte Binding Antigen-175 (EBA- 175) [51], a microneme protein which binds to the sialic acid residue on glycophorins of the RBCs [55]. A merozoite serine protease cleaves band 3, causing a disruption in the cytoskeleton of RBC. This results in mechanical destruction of the RBC through haemolysis [51]. The AMA- 1 also releases coats the surface of non-parasitized RBCs and are cleared by the immune system [55, 51]. Again, the antigens act to down regulate erythropoiesis, and the cumulative effect of these activities seeks to reduce the quantity of RBCs leading to anaemia [48]. Haemolysis of parasitized red cells by the erythrocytic cycle of Plasmodium species, and clearance of deformed parasitized and un-parasitized erythrocytes are the principal causes of malarial induced anemia [7]. Mechanism of clearance of IRBCs is known to be mediated by phagocytosis and complement activation [56]. Notwithstanding, reports show that examination of bone marrow from children with severe anaemia showed hypercellularity, mild to normal erythroid hyperplasia and abnormal features of late erythroid progenitor cells [7, 52, 55]. Haemozoin produced through phagocytosis by bone marrow macrophages has been proposed to cause dyserythropoiesis either through direct accumulation in the bone marrow and generation of reactive toxic species or activation of the innate immune response [7, 56, 57]. Some specific immune responses are implicated in MIA. For instance IRBCs, haemozoin and AMA-1 secreted by Plasmodium species activate monocytic and lymphocytic responses [58]. Proinflammatory and anti-inflammatory mediators, such as tumor necrotic factor (TNF- $\alpha$ ), interferon gamma (IFN- $\gamma$ ), interleukins (IL-1 and IL-23) [59], chemokines and growth factors are produced and these contribute to anaemia [48, 52]. Macrophage migration inhibiting factor (MIF) and nitric oxide are found to be higher in severe malaria and they are known to be potential bone marrow suppressors and erythropoietic inhibitors which lead to myelodysplastic syndromes [60-62].

\section{PATHOPHYSIOLOGY OF MALARIA ON PREGNANCY}

It has been reported by several researchers that MiP is more profound in primigravidae mothers, and is one of the factors that bring about pre-term delivery and low birth weight (LBW) [22, 34, 52, 63]. With the issues of stillbirth, an association between the risk of preterm delivery and the occurrence of a malaria infection within the last two weeks of pregnancy was observed in a cohort studied in Uganda [54, 64]. In the same cohort, there was also association between MiP and shortened gestation. Certainly, MiP is one of the major causes of miscarriages in malaria endemic areas in non-immune mothers [54].This could be associated with systemic inflammation (fever) caused by Plasmodium parasites upon the release of glycolipid material into the blood stream, which mediates the release of proinflammatory cytokines such as IL-6, IL-8, IL-12 and IL-18 [56, 63]. The glycolipid material activates inflammatory response signaling cascade of events through toll-like receptors 2 (TLR-2) and this reaction also results in the release of prostaglandins through the COX-2 pathway [63]. Prostaglandins bind to distinct transmembrane receptors on uterine smooth muscle which operate through G-proteins coupled receptors (GPCR), activate adenylate cyclase and stimulate phospholipase C [65]. This causes an enhanced formation of diacylglycerol (DAG) and inositol 1,4,5trisphosphate (IP-3) [64]. These series of reactions result in increased intracellular calcium which causes vigorous uterine contraction which will ultimately bring about the expulsion of the fetus, thereby inducing miscarriages. Cytoadhesion and sequestration cause by IRBCs in umbilical vessels result in knot formation in umbilical cord which eventually reduces placental blood perfusion [13-15]. As a result, there is a reduced oxygen and nutrient delivery to the developing baby leading to preterm delivery, intrauterine growth retardation, low birth weight, fetal anemia and perinatal mortality [13, 21, 50,65]. This also may result in placental ischemia and fetal hypoxia due to low oxygen supply, and this could bring about cell death by apoptosis and necrosis.

\section{MALARIA INDUCED PLACENTAL PATHOLOGY}

Placental malaria (PM) is one major complications of $\mathrm{MiP}$, and is usually associated with low birth weight due to intrauterine growth retardation, preterm delivery, stillbirths, maternal anaemia and mortality [66, 67]. PM results from accumulation of parasitized red blood cells (PRBCs) in the placental vessels. Research has associated this finding with a prominent monocytic inflammatory response that entails increased interferon gamma $(\mathrm{IFN}-\gamma)$ and tumor necrotic factor (TNF) production and enhanced levels of macrophage inducing proteins (MIP- $1 \alpha \&$ MIP-1 $\beta$ ) [12, $58,68-71]$, which are in turn associated with spontaneous abortion, 
premature labor, IUGR and other poor pregnancy outcomes [26, 27]. The severity of placental pathological manifestations is associated with gravidity, immunity [66], and the Plasmodium species involved. One of the mechanisms by which Plasmodium cause PM is excessive complement system activation using the C5a pathway [29]. The histopathological disfiguration may be presented differently depending on the severity of the condition, species involved and level of parasitaemia. In regions of high endemicity, where acquired immunity is high, asymptomatic infections commonly result in several placental pathologies [3, 13]. Most of these histopathological observations are as a result of tissue sequestration. Sequestration of infected erythrocytes in placenta is mediated by VAR2CSA, a Plasmodium erythrocyte membrane protein 2 variant that binds to chondroitin sulfate A (CSA) on the syncytiotrophoblast [3, 72]. What makes the Plasmodium parasites particularly virulent is their exceptional ability to operate as adhesins and insert proteins into the membrane of the IRBCs. These adhesins, $P$. falciparum erythrocyte membrane protein 1 (PfEMP1) proteins, repetitive interspersed family (RIFIN) proteins, subtelomeric variable open reading frame (STEVOR) proteins [73], and surface associated interspersed gene family (SURFIN) proteins bind various receptors in the host microvasculature allowing the infected erythrocytes to sequester and avoid clearance by the spleen [74]. The VAR2CSA belongs to the PfEMP1 family and is the main parasite ligand that mediates placental tissue binding [75]. Antibody-mediated immunity to placental malaria is acquired during successive pregnancies, but the target of VAR2CSAspecific protective antibodies is still under investigation [74]. In non-immune mothers, transplacental transfer of parasites can occur in which case, the fetus is at risk of contracting the infection $[74$, 75].

Studies conducted elsewhere shows that placental malaria reduces the gross placental weight averagely of 5.6\% [76]. Histopathological evidences show varieties of placental derangement in laboratory models which are also known to occur in human. These histopathological changes range from syncytiotrophoblast thickening, reduction of decidua basalis, fibrin deposition, thrombi formation, haemosiderin deposition, mononuclear cell infiltration, to tissue destruction [71]. H\&Estained sections reveal variable degrees of localized trophoblast layer thickening, placental tissue disorganization and associated necrotic foci in the labyrinth zone and thrombi as compared to non-infected placentas [68]. Usually, there is evidence of necrosis and haemosiderosis in the decidua basalis (maternal portion) of the placenta and the intervillous space respectively. The presence of haemosiderin in the intervillous space is as a result haemolysis of maternal RBCs to release iron which accumulates and form Prussian blue upon staining. Again, Plasmodium in PRBCs in the placenta also ferment glucose to form lactic acid and mediate the release of stress related reactive oxygen species which all contribute to necrosis in the decidua basalis $[68,71,76$,].

Studies conducted in southeastern Tanzania reported certain histological changes in placentas infected with the
Plasmodium parasite. There were moderate to severe mononuclear intervillositis, polymorphonuclear leukocytosis and focal placental calcifications in the stroma which were associated with an increased risk of IUGR, LBW and preterm delivery [77]. The study also reported that inflammatory infiltration of the intervillous spaces is associated with LBW especially when mononuclear cells are highly increased [25]. The presence of massive mononuclear intervillositis (MMI) in the placenta was also associated with a 4-fold increase in the risk of LBW [78] which is a possible cause of placental insufficiency due to blockage by PRBCs either in the decidua basalis or knot formed in the umbilical vessels [79]. There is the possibility of acute chorioamnionitis occurring in PM due to leukocytosis that results in malaria but there is currently no scientific evidence $[80,81]$.

In severe cases, the placenta villi show signs of inflammation (granulomatous villitis) [66]. Again, study conducted at Karen in Thailand indicated that about $1.7 \%$ of PM cases exhibit massive chronic intervillositis (MCI) which were all found in primigravid mothers with acute symptomatic $P$. falciparum infection. Thrombi formation due to cytoadhesion, vascular sequestration in the umbilical vessels results in knot formation in the cord [82]. This sometimes results in placental infarction, IUGR, intrauterine hypoxia, premature birth or miscarriage and neurologic injury such as neonatal stroke. Intrauterine hypoxia is the major cause of chorangiosis and chorangiomatosis which predisposes infants to certain congenital anomalies [81-83]. Hypoxic fetal stress in utero in the late third trimester can result in the passage of meconium into the amniotic fluid [84], which results in deep green discoloration of the chorionic plate. Meconium associated umbilical vessel myonecrosis has been associated with poor CNS development [85, 86]. Study shows that placental and cord pathologies such as elevated nucleated red blood cells and fetal thrombotic vasculopathy are strongly associated with higher illness severity during the first $24 \mathrm{hrs}$ in babies born of preterm (premature babies) [87].

\section{EFFECT OF MIP ON FETAL NEURODEVELOPMENT}

It must be emphasized that vertical transmission of malaria sometimes occurs in non-immune primigravid mothers when malaria parasites cross the placenta [88]. Once they enter the fetal circulation, the malaria parasite can travel anywhere in the body. One major targets here is the brain, resulting in cerebral malaria (CM). $\mathrm{CM}$ is defined as an acute, symmetric encephalopathy associated with sequestration of parasitized erythrocytes in cerebral vessels in patients with $P$. falciparum [89, 90]. Clinical presentation of headache, vomiting and convulsion are common in CM. Research has shown that rosetting, clumping and cytoadhesion in cerebral vessels can facilitate thrombus formation and subsequently result in cerebrovascular accident and other neuropsychiatric manifestations [88-91]. We hypothesis, that aneurismal dilatation could occur in the pre-thrombotic vessels, which may subsequently cause hemorrhage leading to 
developmental abnormalities in the brain and in extreme cases, death of the fetus may ensue. Research has also shown a significant deterioration of the blood brain barrier (BBB) in animal models with CM [30, 92]. The BBB is a structural and functional barrier that limits the transport of substances between the blood and some specific parts of the brain. Studies on CM models show disorganized alignment of tight junctions between adjacent cells, increased vessel permeability, and increased transcytosis of molecules across the endothelium, though the mechanism is not fully understood [93, 94]. The most striking example of BBB disruption is the presence of hemorrhage, which has been noted in the white matter in fatal CM [95-97]. Any disruption in the white matter might affect brain nuclei development which will in a long term appreciably affect mental functioning. Studies on adults in Vietnam and children in Malawi have shown reduced expression of tight-junction proteins in fatal CM [6, 97]. However, the studies showed no effect of MiP on fetal cortical development or supratentorial volume, except that the cingulate gyrus matured comparatively faster [6, 98, 99]. Hyperthermia is one of the common symptoms of malaria, and research has shown that maternal hyperthermia in their early stage of the first trimester of pregnancy is associated with increased risk of neural tube defects and may act as a human teratogen [100]. It must be emphasized that a defective neural tube can consequently affect CNS functioning, and malaria which could be a predisposing factor is no exception. Occasionally, frankly psychotic behaviour is the first manifestation of cerebral involvement and the level of consciousness may fluctuate over a period of hours [101].

\section{IMMUNOMODULATION AND MIP}

During pregnancy, partial maternal immunosuppression occurs to accommodate fetus. This is caused by suppressing the effect of the cell mediated immune pathway, with total dominance of the humoral immune system (antibody mediated), which is not effective in fighting intracellular pathogens including the Plasmodium [102]. This suppression has been linked with high cortisol secretion, a typical immunosuppressive hormone, during pregnancy in humans and other primates [103, 104]. Malaria infection and level of parasitaemia are completely associated to cortisol levels in primigravid women $[105,106]$. This effect taken into consideration makes pregnant women especially in their first three months, more susceptible to malaria.

Placental malaria has also been associated with poor cytokine production by T-cells and induced tolerance to Plasmodium antigens which may be associated with the induction of regulatory $\mathrm{T}$ cells in PM-exposed infants [30, 93]. Most placental pathology is known to be caused by sequestration in vascular endothelium via the universal endothelial surface proteins intercellular adhesion molecule-1 (ICAM-1), CD36, chondroitin sulphate A (CSA), cytokines, monocytes and hyaluronic acid largely expressed in the placental endothelium [107]. The presence of cytokines in the decidua basalis predisposes fetus to fetal inflammatory response syndrome (FIRS) and some fetal morphologic abnormalities, including ventriculomegaly and hemorrhages [108]. When severe malaria is poorly or not treated during pregnancy, the newborn suffers the consequence. In the case of impaired feto-maternal transfer, there is also a reduced passive immunity transfer from mother to fetus [108, 109]. Currently, there is little evidence of immunosuppressive effect of malaria in newborn. Research indicates that infants in malaria endemic regions response very slow to malaria immunization. This is believed to be as a result of down regulation of the feeble immune system of the newborn [109]. However, the understanding of this mechanism is not clear.

\section{THE WAY FORWARD}

The WHO in partnership with Roll Back Malaria has put several mechanisms and recommendations in place to reduce the global prevalence of malaria and MiP to be specific.

Ghana's MIP program is coordinated by the President Malaria Initiative (PMI), National Malarial Control Program (NMCP) and Family Health Division of the Ghana Health Service in the implementation process of WHO recommendations in Ghana. Some of these recommendations include sleeping under Insecticide Treated Bed Nets (ITBNs). This was to reduce the rate of mosquito-person contact and hence reduce malaria transmission. Intermittent prevention and treatment was also recommended for areas of stable transmission and endemic regions. In areas of low endemicity where there is little or no acquired immunity, it is advised that prompt attention should be given to pregnant women with early signs and symptoms of malaria. There is currently an extensive research on VAR2CSA and its contribution to placental sequestration. This is now being made into a pregnancy malaria specific vaccine for non-immune mothers. In 2007, the UNICEF started to support a pilot implementation of a new and promising malaria prevention strategy called "intermittent preventive treatment during pregnancy and infants with sulphadoxine-pyrimethamine (IPTpSP) and (IPTi-SP)". It is recommended that this key intervention for pregnant women and infants, combined with ITBN use and effective case management, should remain a priority across stable malaria transmission countries. This strategy involves the provision of curative doses of an antimalarial (sulphadoxinepyrimethamine) to pregnant women and infants as they attend routine prenatal clinics and childhood immunization at the various antenatal clinics (ANCs) respectively. Provision of folic acid, vitamin B12 and iron supplements for pregnant women routinely has also help reduce maternal anaemia during pregnancy. These together with the principles and context of the MDG project, the burden of MiP will gradually be a thing of the past in the near future.

\section{SUMMARY}

Maternal malaria in malaria endemic regions still remains a major public health problem and contributes to infant 
mortality in developing countries especially in Sub-Sahara Africa. Studies have shown gross pathological and histopathological evidence of placental disturbances in MiP which is strongly linked with placental tissue sequestration mediated by the VAR2CSA. Some of these include thrombi formation in the umbilical cord leading to knot formation, syncytiotrophoblast thickening and reduction of decidua basalis, fibrin and hemosiderin deposition in the intervillous space, mononuclear cell infiltration, and disruption of the bloodplacental-barrier. These placental tissue derangements as well as associated necrosis foci in the labyrinth zone and the umbilical knot formation predispose the unborn baby to pre-natal and post-natal health challenges. Some of these challenges include clinical symptoms such as preterm delivery, LBW, IUGR, poor neurodevelopment, peri-villous fibrosis, leukocytosis, pregnancy associated anaemia, labour complications and immunosuppression in newborns, which require prompt clinical attention. There is therefore the need to consider MiP as an emergency case to ensure appropriate safety of both the mother and the baby.

Physical examination and clinical presentations as the basis for accessing malaria status of pregnant women in clinical settings are not reliable and conclusive enough. We therefore recommend microscopy, rapid diagnostic test (RDT) and Polymerase chain reaction (PCR) as the best laboratory diagnostic procedures in both high and low malaria transmission zones.

\section{Financial support and sponsorship: Nil.}

Conflict of Interests: There are no conflicts of interest.

\section{REFERENCES}

1. Sha'a KK, Oguche S, Watila IM, Ikpa TF. In vitro antimalarial activity of the extracts of Vernonia amygdalina commonly used in traditional medicine in Nigeria. Science World Journal, 2011; 6(2):59.

2. World Health Organization: World Malaria Report. Switzerland, 2015; 1-2.www.who.int/malaria/

3. Ndam NT, Denoeud-Ndam L, Doritchamou J, Viwami F, Salanti A, Nielsen M.A, et al. Protective antibodies against placental malaria and poor outcomes during pregnancy, Benin. Emerging Infectious Diseases. 2015; 21(5):http://dx.doi.org/10.3201/eid2015

4. Samak AC. Malaria in pregnancy: an overview. McGill Journal of Medicine. 2004; 8: 66-71.

5. Chen C. Development of antimalarial drugs and their application in China: a historical review. BioMed Central Ltd, 2014; http://www.idpjournal.com/content/3/1/9.

6. Walther B, Miles DJC, Waight P, Palmero SM, Ojuola O, Touray ES, et al. Placental malaria is associated with attenuated CD4 T-cell responses to tuberculin PPD 12 months after BCG vaccination. BMC infectious diseases. 2012; 12(6): 1-7.

7. Autino B, Corbett Y, Castelli F, Taramelli D. Pathogenesis of Malaria in Tissues and Blood. Mediterranean Journal of Hematology and Infectious Disease. 2012; 4(1):1-12.

8. Wahlgren M, Treutiger CJ, Gysin J. Cytoadherence and rosetting in pathogenesis of severe malaria: Malaria molecular and clinical aspects. The Netherlands: Harwood Academic Publishers. 1999; pp 289-328.

9. Schofield L, Grau GE. Immunological processes in malaria pathogenesis. Nature Reviews Immunology. 2005; 5(9): 722-735.

10. Dondorp AMC. Direct In Vivo Assessment of Microcirculatory Dysfunction in Severe Falciparum Malaria. Journal of Infectious Diseases. 2008; 197(1): 79-84.
11. Jayakumar PS, Demba S, Geoffrey S, Tamas S, Moore JM. MalariaInduced Murine Pregnancy Failure: Distinct Roles for IFN- $\gamma$ and TNF. Journal of Immunology. 2009; 183(8):5342-5349.

12. David PH, Hommel M, Miller LH, Udeinya IJ, Oligino LD. Parasite sequestration in Plasmodium falciparum malaria: spleen and antibody modulation of cytoadherence of infected erythrocytes. Proceedings of the National Academy of Sciences U.S.A. 1983; 80(16): 5075-5079.

13. Costa FTM, Avril M. Cytoadhesion of Plasmodium falciparuminfected erythrocytes and the infected placenta: a two-way pathway. Brazilian Journal of Medical and Biological Research. 2006; 39(12): 1525-1536.

14. Guyatt HL and Snow R.W. Malaria in pregnancy as an indirect cause of infant mortality in sub-Saharan Africa. Transactions of the Royal Society of Tropical Medicine and Hygiene. 2001; 95(6):569-576.

15. Desai MO, Kuile F, Nosten F, McGready R, Asamoa K, Brabin B, et al. Epidemiology and burden of malaria in pregnancy. Infectious Disease. 2007; 7(2):93-104.

16. Falade CO, Tongo OO, Ogunkunle OO, Orimadegun AE. Effects of malaria in pregnancy on newborn anthropometry. The Journal of Infection in Developing Countries. 2010; 4(7):448-453.

17. Raimi OG \&Kanu CP. The prevalence of malaria infection in pregnant women living in a suburb of Lagos, Nigeria.African Journal of Biochemistry Research.2010; 4(10): 243-245.

18. Gunn JKL, Ehiri JE, Jacobs ET, Ernst KE, Pettygrove S, Kohler LN et al. Population-based prevalence of malaria among pregnant women in Enugu State, Nigeria: the Healthy Beginning Initiative.Malaria Journal. 2015;14(438):DOI 10.1186/s12936-0150975-x

19. Eijk AMV, Noor AM, Snow RW, Kuile FO. Prevalence of malaria infection in pregnant women compared with children for tracking malaria transmission in sub-Saharan Africa: a systematic review and meta-analysis. The Lancet Journals. 2015; 3(10):DOI: http://dx.doi.org/10.1016/S2214-109X(15)00049-2.

20. President's Malaria Initiative Report; Ghana Malaria Operational Plan FY 2015. www.pmi.gov/where-we-work/ghana

21. Rovira-Vallbona E, Monteiro I, Bardaj1' A, Serra-Casas E, Neafsey DE, Quelhas D. et al. VAR2CSA Signatures of High Plasmodium falciparum Parasitaemia in the Placenta.PLoS ONE. 2013; 8(7): e69753. doi:10.1371/journal.pone.0069753

22. Rogerson SJ, Brown HC, Cooke BM, Brown GV. Placental tumor necrosis factor alpha but not gamma interferon is associated with placental malaria and low birth weight in Malawian women. Infection and Immunity. 2003; 71(1): 267-70.

23. Gustavo CR and Senanayake N. Neurological manifestations of malaria. Arqneuro- Psiquiat. 1992; 50(1):273-274.

24. Dondorp AM, Fanello CI. Artesunate versus quinine in the treatment of severe falciparum malaria in African children (AQUAMAT): an open-label, randomised trial. The Lancet. 2010; 376(9753):16471657

25. Bardaji A, Sigauque B, Sanz S, Maixenchs M, Ordi J, Aponte JJ, et al. Impact of Malaria at the End of Pregnancy on Infant Mortality and Morbidity. Journal of Infectious Disease. 2011; 203(5):691-699.

26. Menendez C, Ordi J, Ismail M.R, Ventura PJ, Aponte JJ, Kahigwa E, et al. The impact of placental malaria on gestational age and birth weight. Journal of Infectious Diseases. 2000; 181(5):1740-1745.

27. Kalilani L, Mofolo I, Chaponda M, Rogerson SJ, Meshnick SR. The effect of timing and frequency of Plasmodium falciparum infection during pregnancy on the risk of low birth weight and maternal anemia. Transactions of the Royal Society of Tropical Medicine and Hygiene. 2010; 104(6): 416-422.

28. Huynh BT, Fievet N, Gbaguidi G, Dechavanne S, Borgella S, GuezoMevo B et al. Influence of the timing of malaria infection during pregnancy on birth weight and on maternal anemia in Benin. American Journal of Tropical Medicine and Hygiene. 2011; 85(2): 214-220.

29. Valea L, Tinto H, Drabo MK, Huybregts L, Sorgho H, Ouedraogo $\mathrm{JB}$, et al. An analysis of timing and frequency of malaria infection during pregnancy in relation to the risk of low birth weight, anaemia 
and perinatal mortality in Burkina Faso. Malaria Journal. 2012; 11(71). doi:10.1186/1475-2875-11-71.

30. Conroy A. Biomarkers of Severe Malaria: Complement Activation and Dysregulated Angiogenesis in Placenta Malarial and Cerebral Malaria. PhD thesis.2012.http://hdl.handle.net/1807/32064.

31. Prudencio M, Rodriguez A, Mota MM. Silence path to thousands of merozoites: the Plasmodium liver stage. Nature Reviews Microbiology. 2006; 4(11): 849-856.

32. Pierre AB, Safeukui I, Deplaine G, Brousse V, Prendki V, Thellier M. The pathogenesis of Plasmodium falciparum malaria in humans: insights from splenic physiology. Blood. 2011; 117(2): 381-392.

33. Faiz MA, Rahmani MR, Hossain MA, Rashid HA. Cerebral MalariaA Study of 104 Cases. Bangladesh. Bangladesh Medical Research Council Bulletin.1998; 24(2): 35-42.

34. Ogino S, Redline RW. Villous capillairy lesions of the placenta: distinctions between chorangioma, chorangiomatosis and chorangiosis, Human Pathology. 2000; 31(8): 945-954.

35. McGready RBB, Davison K, Stepniewska T, Cho H, Shee A, Brockman A, et al. The effects of Plasmodium falciparum and $P$. vivax infections on placental histopathology in an area of low malaria transmission. American Journal of Tropical Medicine and Hygiene. 2004; 70(4): 398-407.

36. Chen C. Development of antimalarial drugs and their application in China: a historical review. Infectious Diseases of Poverty. 2014; 3(9): 1-10.

37. Dondorp AMM, Nyanoti M, Kager PA, MithwaniS,Vreeken J, Marsh $\mathrm{K}$. The role of reduced red cell deformability in the pathogenesis of severe falciparum malaria and its restoration by blood transfusion. Transactions of the Royal Society of Tropical Medicine and Hygiene. 2002; 96(3): 282-286.

38. Anand AC and Puri P. Jaundice in malaria. Journal of Gastroenterology and Hepatology. 2005; 20(9):1322-1332.

39. Shivakumar B.G, and Sekhar S.P. Renal and hepatic derangements in malaria with clinical outcome. Indian Journal of Basic and Applied Medical Research. 2015; 4(2): 528-534.

40. Ashraf $M$ and Fahad SA. Study Correlating the Derangement of Liver Function Tests in Vivax and Falciparum Malaria. IOSR Journal of Dental and Medical Sciences. 2014; 13(8): 81-84.

41. Kochar DK, Singh P, Agarwal P, Kochar S.K, Pokharna R, SareenP.K.Malarial hepatitis. Journal Association of Physicians of India. 2003; 51: 1069-1072.

42. Asante D, Ameyaw OA, Effah-Yeboah E, Gyamenah AP, Djabanor J. Hepatoprotective effect of ethanolic leaf extracts of Abrusprecatoriusin Plasmodium bergheiinfected imprinting control region (ICR) mice; A histopathological perspective. International Journal of Biological and Pharmaceutical Research. 2015; 6(10): 814-821.

43. Bhalla A, Suri V, Singh V. Malarial hepatopathy. Journal of Postgraduate Medicine. 2006; 52: 315-320.

44. Gupta BK, Sharma K, Nayak KC, Agrawal TD, Binani A. A case series of splenic infarction during acute malaria in northwest Rajasthan, India. Transactions of the Royal Society of Tropical Medicine and Hygiene. 2010; 104(1):81-83.

45. Kim EM, Cho HJ, Cho CR, Kwak YG, Kim MY, Abdominal computed tomography findings of malaria infection with Plasmodium vivax. American Journal of Tropical Medicine and Hygiene. 2010; 83(6): 1202-1205.

46. Siqueira MA, Magalha BML, Melo GC, Ferrer M, Castillo P, MartinJaular L, et al. Spleen Rupture in a Case of Untreated Plasmodium vivax Infection. PLoS Neglected Tropical Diseases. 2012; 6(12):1934-1939.

47. Taylor SM, Cerami C, Fairhurst SM. Hemoglobinopathies: Slicing the Gordian KnotofPlasmodium falciparum Malaria Pathogenesis. Plos Pathogens. 2013; 9(5): e1003327. doi:10.1371/journal.ppat.1003327.

48. Mokashi AJ, Shirahatti RG, Prabhu SK, Va-gholkar K.R. Pathological rupture of malarial spleen. Journal of Postgraduate Medicine. 1992; 38(3): 141-142.
49. Rizwan F, Qamarunisa H, Memon A. Prevalence of anemia in pregnant women and its effects on maternal and fetal morbidity and mortality. Pakistan Journal Medical Sciences. 2010; 26 (1): 92-95.

50. Boampong JN, Karikari AA, Ameyaw OE. In vivoantiplasmodial and in vitro antioxidant properties of stem bark extracts of Haematostaphisbarteri. Asian Pacific Journal Tropical Biomedicine. 2015; 5(6): 446-450.

51. Oue'draogo S, Koura GK, Bodeau-Livinec F, Accrombessi MMK. Maternal Anemia in Pregnancy: Assessing the Effect of Routine Preventive Measures in a Malaria-Endemic Area. American Journal Tropical Medicine Hygiene. 2013; 88(2): 292-300.

52. Zuccala ES, Baum J. Cytoskeletal and membrane remodeling during malaria parasite invasion of the human erythrocyte. British Journal of Haematology. 2011; 154(6): 680-689.

53. Gysin J, Pouvelle B, Le Tonqueze M, EdelmanL, Boffa M.C. Chondroitin sulfate of thrombomodulin is an adhesion receptor for Plasmodium falciparum-infected erythrocytes. Molecular and Biochemical Parasitology. 1997; 88(1): 267-271.

54. Dorman EK, Shulman CE. Impaired uteroplacental blood flow in pregnancies complicated by falciparum malaria. Ultrasound Obstetric Gynecology. 2002; 19(2): 165- 670.

55. De Beaudrap P, Turyakira E, White LJ, Nabasumba C, Tumwebaze $\mathrm{B}$, Muehlenbachs A, et al. Impact of malaria during pregnancy on pregnancy outcomes in a Ugandan prospective cohort with intensive malaria screening and prompt treatment. Malaria Journal. 2013; 12(139): 10-1186.

56. Nweneka CV, Doherty CP, Cox S, Prentice A. Iron delocalization in the pathogenesis of malarial anaemia. Transaction of the Royal Society of Tropical Medicine and Hygiene; 2010; 104(3): 175-84.

57. Skorokhod OA, Caione L, Marrocco T, Migliardi G, Barrera V, Arese $\mathrm{P}$ et al. Inhibition of erythropoiesis in malaria anemia: role of hemozoin and hemozoin-generated 4- hydroxynonenal. Blood. 2010; 116: 4328-4337.

58. Cowman FA, Drew F, Jake B. The cellular and molecular basis for malaria parasite invasion of the human red blood cell. Journal of Cell Biology. 2012; 198(6): 961-971

59. Musumeci G, Castrogiovanni P, Trovato FM, Parenti R, Szychlinska MA, Imbesi R. Pregnancy, embryo-fetal development and nutrition physiology around fetal programming. Journal of Histology and Histopathology. 2015; 2(1):1-6.

60. McDevitt MM, Xie J, Shanmugasundaram G, Griffith J, Liu A, McDonald C. et al. A critical role for the host mediator macrophage migration inhibitory factor in the pathogenesis of malarial anaemia. Journal of Experimental Medicine. 2006; 203(5): 1185-1196.

61. Ghosh K, Ghosh K. Pathogenesis of anemia in malaria: a concise review. Parasitology Research. 2007; 101(6): 1463-1469.

62. Pradhan P. Malarial anaemia and nitric oxide induced megaloblastic anaemia: a review on the causes of malarial anaemia. Journal of Vector Borne Disease. 2009; 46(2): 100- 108.

63. Harvey RA, Champe PC. Pharmacology, 4th Edition, 2009, Lippincott Williams and Wilkins,Florida. Pp 501-503.

64. Hviid L. The immuno-epidemiology of pregnancy-associated Plasmodium falciparum malaria: a variant surface antigen-specific perspective. Parasite Immunology. 2004;26(12): 477-486.

65. Aribodor DN, Nwaorgu OC, Eneanya CI, Okoli I, Pukkila-Worley R, Etaga HO, Association of low birth weight and placental malarial infection in Nigeria. Journal of Infections in Developing Countries. 2009; 3(8): 620-623.

66. Berendt AR, Ferguson DJ, Newbold CI, Sequestration in Plasmodium falciparum malaria: sticky cells and sticky problems. Parasitology Today. 1990; 6(8): 247-254.

67. Nosten F, Rogerson SJ, Beeson JG, McGready R, Mutabingwa TK, Brabin B. Malaria in pregnancy and the endemicity spectrum: what can we learn? Trends in Parasitology. 2004; 20(9): 425-432.

68. Rowe JA, Kyes SA. The role of Plasmodium falciparum var genes in malaria in pregnancy. Molecular Microbiology. 2004; 53(4): 10111019.

69. Neres R, Marinho CRF, Gonçalves LA, Catarino MB, PenhaGonçalves C. Pregnancy outcome and placenta pathology in 
Plasmodium bergheiANKA infected mice reproduce the pathogenesis of severe malaria in pregnant women. PLoS One. 2008; 3(2):e1608.

70. Rodrigues-Duarte L, de Moraes LV, Barboza R, Marinho CRF, Franke-Fayard B, Janse CJ et al. Distinct placental malaria pathology caused by different Plasmodium bergheilines that fail to induce cerebral malaria in the C57BL/6 mouse. Malaria Journal. 2012;11(231): 1-9.

71. Redline RW. Elevated circulating fetal nucleated red blood cells and placental pathology in term infants who develop cerebral palsy. Human Pathology. 2008; 39(9): 1378-1384.

72. Brabin BJ. Congenital malaria: a recurrent problem. Annals of Tropical Paediatrics. 2007; 27(2): 95-98.

73. Khunrae P, Dahlbäck M, Nielsen MA, Andersen G, Ditlev SB, Resende $\mathrm{M}$, et al. Fulllength recombinant Plasmodium falciparum VAR2CSA binds specifically to CSPG and induces potent parasite adhesion-blocking antibodies. Journal of Molecular Biology. 2010; 397:826-834

74. Clausen TM, Christoffersen S, Dahlbäck M, Langkilde AE, Jensen KE, Resende MA. et al. Structural and functional insight into how the Plasmodium falciparum VAR2CSAprotein mediates binding to chondroitin sulfate A in placental malaria. J. Biol. Chem.2012; 287: 23332- 23345.

75. Beaudet JM, Mansur L, Joo EJ, Kamhi E. Yang B, Clausen TM, et al. Characterization of human placental glycosaminoglycans and regional binding to VAR2CSA in malaria infected erythrocytes. Glycoconj J. 2014; 31:109-116

76. Gnidehou S, Doritchamou J, Arango EM, Cabrera A, Arroyo MI, Kain KC, et al. Functional Antibodies against VAR2CSA in Nonpregnant Populations from Colombia Exposed to Plasmodium falciparum and Plasmodium vivax. Infect. Immun. 2014; 82(6):25652571.

77. Khong YT, Bendon RW, Qureshi F, Redline RW, Gould S, Stallmach T, et al. Chronic deciduitis in the placental basal plate: definition and inter observer reliability. Human Pathology. 2000; 31(3): 292-295.

78. Ohyama M, Itani Y, Yamanaka M, Goto A, Kato K, Ijiri R, et al. Maternal, neonatal, and placental features associated with diffuse chorioamniotichaemosiderosis, with special reference to neonatal morbidity and mortality. Pediatrics. 2004; 113(4): 800-805.

79. Watkinson M, Rushton DI. Plasmodial pigmentation of placenta and outcome of pregnancy in West African mothers. British Medical Journal.1983; 287(6387): 251-254.

80. Redline RW, Faye-Petersen O, Heller D, Qureshi F, Savell V, Vogler C. The Society for Pediatric Pathology, Perinatal Section, Amniotic Fluid Infection Nosology Committee. Amniotic infection syndrome: nosology and reproducibility of placental reaction patterns. Pediatric Developmental Pathology. 2003; 6(5): 435-448.

81. Redline RW, Boyd T, Campbell V, Hyde S, Kaplan C, Khong TY, et $a l$. The Society for Pediatric Pathology, Perinatal Section, Maternal Vascular Underperfusion Nosology Committee. Maternal vascular underperfusion: nosology and reproducibility of placental reaction patterns. Pediatric Developmental Pathology. 2004; 7(3): 237-249.

82. Conroy A, Serghides L, Finney C, Owino SO, Kumar S, Gowda DC, et al. C5a enhances dysregulated inflammatory and angiogenic responses to malaria in vitro: potential implications for placental malaria. PLoS One. 2009; 4(3):e4953.

83. Persson KE, McCallum FJ, Reiling L, Lister NA, Stubbs J, Cowman $\mathrm{AF}$, et al. Variation in use of erythrocyte invasion pathways by Plasmodium falciparum mediates evasion of human inhibitory antibodies. Journal of Clinical Investigation. 2008; 118(1): 342-351.

84. Fox H, Sebire NJ. Pathology of the Placenta-Major Problems in Pathology. 3rd Edition, Saunders-Elsevier, 2008.

85. Redline RW, O'Riordan MA. Placental lesions associated with cerebral palsy and neurologic impairment following term birth. Archieves of Pathology and Laboratory Medicine. 2000; 124(12): $1785-1791$.
86. Redline RW. Severe fetal placental vascular lesions in term infants with neurologic impairment. Journal of Obstetric Gynecology. 2005; 192(2): 452-457.

87. Roescher AM, Hitzert MM, Timmer A, Verhagen EA, Erwich JJHM, Bos AF. Placental pathology is associated with illness severity in preterm infants in the first twenty-four hours after birth. Early Human Development. 2011; 87(4): 315-319.

88. Steketee RW, Wirima JJ, Hightower AW. The effect of malaria and malaria prevention in pregnancy on offspring birth weight, prematurity and intrauterine growth retardation in rural Malawi. American Journal of Tropical Medicine and Hygiene. 1996; 55(11): $33-41$.

89. D'Alessandro U, Langerock P, Bennet S, Francis N, Cham K, Greenwood BM. The impact of a national bed net program on the outcome of pregnancy in primigravidae in The Gambia. Transaction of the Royal Society of Tropical Medicine and Hygiene.1996; 90: 487-492.

90. Armulik A, Genove G. Pericytes regulate the blood-brain barrier. Nature. 2010; 468(7323): 557-561.

91. Dondorp A, Nosten F. Artesunate versus quinine for treatment of severe falciparum malaria: a randomised trial. Lancet. 2005; 366(9487): 717-725.

92. Riganti M, Pongponratn E. Human cerebral malaria in Thailand: a clinico-pathological correlation. Immunology Letters. 1990; 25(1): 199-205.

93. Patankar TF, Karnad DR. Adult Cerebral Malaria: Prognostic Importance of Imaging Findings and Postmortem Findings. Radiology. 2002; 224(3): 811-816.

94. Daneman R, Zhou L. Pericytes are required for blood-brain barrier integrity during embryogenesis. Nature. 2010; 468(323): 562-566.

95. Brown HC, Chau TT. Blood-brain barrier functions in cerebral malaria and CNS infections in Vietnam. Neurology. 2000; 55(1): 104-111.

96. Brown H, Rogerson S. Blood-brain barrier functions in cerebral malaria in Malawian children. American Journal of Tropical Medicine and Hygiene. 2001; 64(3): 207-213.

97. White VA, Lewallen S. Correlation of retinal haemorrhages with brain haemorrhages in children dying of cerebral malaria in Malawi. Transaction of the Royal Society of Tropical Medicine and Hygiene. 2001; 95(6): 618-621.

98. Rijken MJ, de Wit CM, Mulder EJH, Kiricharoen S, Karunkonkowit $\mathrm{N}$, Paw T, et al. Effect of malaria in pregnancy on fetal cortical brain development: a longitudinal observational study. Malaria Journal. 2012; 11(222):1-6.

99. Lieberman E, Lang J, Richardson DK, Frigoletto FD, Heffner LJ, Cohen C. Intrapartum Maternal Fever and Neonatal Outcome. Pediatrics. 2000; 105(8):8-13.

100. Moretti ME, Bar-Oz B, Fried S, Koren G. Maternal hyperthermia and the risk for neural tube defects in offspring systematic review and meta-analysis. Epidemiology. 2005; 16(2): 216- 219.

101. Medana M, Hien TT. The clinical significance of cerebrospinal fluid levels of kynurenine pathway metabolites and lactate in severe malaria. Journal of Infectious Disease; 2002; 185(5): 650-656.

102. Jamieson DJ, Theiler RN, Rasmussen SA. Emerging Infections and Pregnancy. Emerging Infectious Diseases. 2006; 12(11): 1638-1643.

103. Szekeres-Bartho J. Immunological relationship between the mother and the fetus. International Review of Immunology. 2002; 21(6): 471-495.

104. Takem EN, D'Alessandro U. Malaria in pregnancy. Mediterranean Journal of Hematology and Infectious Disease. 2013; 5(1):1-14.

105. Bouyou-Akotet M.K, Adegnika A.A, Agnandji S.T, Ngou-MilamaE, Kombila M, Kremsner PG, Mavoungou E. Cortisol and susceptibility to malaria during pregnancy. Microbes Infection. 2005; 7(11): 12171223.

106. De Nys HM, Calvignac-Spencer S, Boesch C, Dorny P, Wittig RM, Mundry $\mathrm{R}$, et al. Malaria parasite detection increases during pregnancy in wild chimpanzees. Malaria Journal. 2014; 13(1): 413 419. 
107. Maestre A, Carmona-Fonseca J. Immune responses during gestational malaria: a review of the current knowledge and future trend of research. Journal of Infection in Developing Countries.2014; 8(4): 391-402.

108. Mor G, Cardenas I. The Immune System in Pregnancy: A Unique Complexity. American Journal of Reproductive Immunology. 2010:63(6): 425-433.

109. Miles D, van der Sande M, Crozier S, Ojuola O, Palmero M, Sanneh $\mathrm{M}$, et al. Effect of Antenatal and Postnatal environment on CD4 Tcell Responses to BCG in healthy Gambian infants. Clinical Vaccine Immunology. 2008; 15(6): 995-1002.

How to cite this article:

Djabanor J, Quansah E and Asante DB. Effects of Malaria in Pregnancy (MiP) on Pregnancy Development and its Outcome; a Critical Review. J App Biol Biotech. 2017; 5 (02): 008-016. 